\title{
En desplazamiento forzado: desde Banavil, Tenejapa, hacia San Cristóbal de Las Casas
}

\section{Forced Displacement: from Banavil, Tenejapa to San Cristobal de Las Casas}

\author{
Carolina Pecker Madeo \\ https://orcid.org/0000-0001-9005-697X \\ Instituto de Ciencias Antropológicas, Universidad de Buenos Aires \\ pecker_madeo@hotmail.com
}

\section{Resumen:}

A partir del abordaje etnográfico, en este artículo presento una situación particular de movilidad forzada en los Altos de Chiapas: el desplazamiento de un grupo de indígenas tseltales desde su comunidad en Banavil, municipio de Tenejapa, hacia la ciudad de San Cristóbal de Las Casas por motivos de violencia política. Basándome en el trabajo de campo realizado en los años 2015 y 2018 en la ciudad, propongo analizar el desplazamiento forzado como un proceso de desterritorialización / territorialización precaria, cuyas particularidades caracterizo en vinculación con los sentidos de los propios desplazados acerca de los territorios y las experiencias de violencia, así como con sus identificaciones, objetivos y relaciones con organizaciones en la ciudad.

Palabras clave: desterritorialización, territorialización precaria, violencia política.

\section{Abstract:}

Using an ethnographic approach, in this article I present a particular case of forced mobility in the Highlands of Chiapas: the displacement of a group of Tseltal indigenous people from their community in Banavil, in the Tenejapa municipality to the city of San Cristobal de Las Casas caused by political violence. Based on field work carried out between 2015 and 2018 in this city, I propose to analyze forced displacement as a process of deterritorialization / precarious territorialization whose properties I characterize in relation to the points of view of the displaced themselves, regarding both the territories and the experience of violence, as well as their self-ascriptions, their objectives, and their relation to organizations within the city.

Key words: deterritorialization, precarious territorialization, political violence. 


\section{Introducción}

a ciudad de San Cristóbal de Las Casas, al sureste de México, en el estado de Chiapas, ha sido uno de los destinos frecuentes para campesinos e indígenas provenientes de comunidades de la región de los Altos de Chiapas. Esta movilidad rural-urbana se volvió masiva a partir de la década de 1970, por razones no muy distintas que en el resto de América Latina: «demasiada gente y muy poco trabajo en el campo y la oportunidad de, por lo menos, ganar el salario mínimo y quizás encontrar una vida mejor en la ciudad» (Rus, 2009:170), en un contexto de crisis financiera y agraria que se fue agravando hacia la década de 1980.

Confluyen en estos movimientos de población decenas de miles de indígenas desplazados, empujados a abandonar sus comunidades por conflictos políticos y religiosos, de los cuales la mayoría han encontrado dónde asentarse en localidades rurales del municipio y en el periférico norte de la ciudad, formando un cinturón de colonias o asentamientos indígenas (Cañas, 2011:171) que con el paso del tiempo se extendieron a lo largo de la orilla urbana (Robledo, 2012:110).

Próximos a los caminos periféricos, al pie y sobre un conjunto de cerros, se ubican los asentamientos cuyos principales procesos de ocupación pueden clasificarse según los siguientes dos contextos (Angulo, 2003:69): primero, los conflictos político-religiosos desde la década de 1970, que movilizaron a cerca de 30000 personas, en su mayoría indígenas tsotsiles provenientes del municipio de San Juan Chamula (Martínez, 2005:200), el cual concentró, junto con el de Las Margaritas, 57\% de los conflictos registrados en Chiapas entre 1960 y 2001 (Rivera, 2013:92). Y, segundo, el conflicto armado interno desatado en enero de 1994, a partir del levantamiento del Ejército Zapatista de Liberación Nacional (EZLN) y las ofensivas militares y paramilitares (Chamberlin, 2013), por cuya causa se han desplazado entre 50000 y 84000 personas (Arana y Del Riego, 2012:34).

Esta situación puede caracterizarse, según Nagengast (1994:114), como de violencia política, es decir, que incluye aquellas agresiones que son promovidas (o toleradas) de manera abierta o explícita por agentes del Estado y/u otros actores sociales con intenciones de alcanzar objetivos sociales, étnicos, económicos y/o políticos en el ámbito público o en la vida social en general.

Enmarcado en esta conflictividad, aunque sin intervención directa de fuerzas militares o paramilitares, el caso que abordo en este artículo es el desplazamiento forzado de 21 indígenas tseltales, simpatizantes zapatistas, de la comunidad 
de Banavil municipio de Tenejapa, que se vieron obligados a abandonar sus hogares en diciembre de 2011 a causa de la violencia política ejercida por aquellos a quienes denominan «los priístas», autoridades comunales y personas afines al Partido Revolucionario Institucional (PRI).

Con base en el trabajo de campo realizado en 2015 y 2018 en San Cristóbal de Las Casas, donde aún se hallan en condición de desplazados, propongo el abordaje etnográfico de una modalidad concreta de movilidad forzada, como lo es el desplazamiento forzado interno, fenómeno recurrente ${ }^{1}$ y vigente ${ }^{2}$ en México y en Chiapas, el cual acarrea consecuencias negativas y violaciones a los derechos humanos para todas las personas que lo atraviesan, afectando de manera diferencial a mujeres, niños, adultos mayores e indígenas (Velázquez, 2017:27).

Propongo analizar el desplazamiento forzado como un proceso de desterritorialización / territorialización precaria y caracterizar sus particularidades en vinculación con los sentidos de los propios desplazados, tanto acerca de los territorios y experiencias de violencia como con sus identificaciones, objetivos y relaciones con organizaciones en la ciudad.

1 «En diciembre de 2009, el Centro de Monitoreo de Desplazamiento Interno (IDMC por sus siglas en inglés) del Consejo Noruego sobre Refugiados, reporta la cifra de 115,000 personas. Cifra aportada en su informe publicado en diciembre de 2009 "Mexico: Limited response to displacement following local and regional conflicts". También en el 2009, en la Encuesta Nacional de Victimización y Percepción sobre Seguridad Pública (ENVIPE), se reportó que en un total de 390 hogares mexicanos en 2009, se tomó la decisión de cambiarse de vivienda o lugar de residencia como medida para protegerse de la delincuencia. En 2011, Parametría (Investigación Estratégica Análisis de Opinión y Mercado) en su artículo "México y sus desplazados", señaló la existencia de 1648387 víctimas de DFI. En el 2013 esta CNDH reportó en su Agenda Nacional de Derechos Humanos que, de acuerdo a cifras aportadas por diversas instancias (sin especificar cuáles), se tenía el número de 110000 personas desplazadas, pero que en los últimos dos años (2012-2013), se habían desplazado otras 24 000, y que a ello se debían añadir los 20000 desplazados que reconoció el gobierno de Chiapas, lo que suma un total aproximado de 150000 víctimas de DFI. En el 2015, el Poder Ejecutivo Federal en su Programa Nacional de Atención a Víctimas 2014-2018, retoma la cifra de 150000 personas citando la Agenda Nacional de Derechos Humanos de la CNDH. También en el 2015, el Centro de Monitoreo de Desplazamiento Interno (IDMC por sus siglas en inglés) del Consejo Noruego sobre Refugiados, en su Informe Global 2015: Desplazados internos por los conflictos y la violencia, reportó la existencia de 281400 personas» (CNDH 2016:156-157).

2 De acuerdo con el registro histórico llevado a cabo por la Comisión Mexicana de Defensa y Promoción de los Derechos Humanos (CMDPDH) (2019:15), el total de personas internamente desplazadas por la fuerza en México hasta diciembre de 2018 es de 338 405. En 2018 el desplazamiento forzado interno masivo afectó a 11491 personas en México y el estado de Chiapas concentró 43.82\% del total de la población desplazada del país (CMDPDH 2019:13). 


\section{Desplazamiento forzado: desterritorialización / territorialización precaria}

Lo que distingue las movilidades caracterizadas como «forzadas» de otro tipo de movimientos, como los viajes por turismo o de negocios, es que estas, impulsadas por la violencia, responden a la decisión de proteger la integridad física o enfrentar circunstancias adversas:

De todo el abanico de situaciones posibles, en este texto nos referimos a las movilidades forzadas como resultado de situaciones de violencia que generan altos grados de inseguridad y temor. Es el caso de la delincuencia común, violencia intrafamiliar y de género, homofobia, exclusión, marginación, crimen organizado, narcotráfico y grupos paramilitares o de autodefensa; o también de abusos del propio Estado (Coraza, 2018:2).

En este sentido, y como resultado de situaciones de violencia que implican altos grados de inseguridad y temor, el desplazamiento forzado interno es una forma específica de movilidad forzada cuya dimensión territorial no trasciende fronteras nacionales.

Conforme a los Principios Rectores de los desplazamientos internos (ONU, 1998), aprobados por la Organización de las Naciones Unidas en 1998, en el Artículo 3 de la Ley para la prevención y atención del desplazamiento interno en el estado de Chiapas se define a los desplazados internos como:

personas o grupos de personas asentadas en el Estado de Chiapas que se han visto forzadas u obligadas a abandonar, escapar o huir de su lugar de residencia habitual, en particular como resultado o para evitar los efectos de un conflicto armado, de situaciones de violencia generalizada, de violaciones de los derechos humanos o de catástrofes naturales o provocadas por el ser humano y que no han cruzado los límites territoriales del Estado (Periódico Oficial del Estado de Chiapas, 2012).

El desplazamiento forzado implica entonces un evento dramático, de escape o huida, pero abarca un proceso que lo trasciende, ya que sus efectos perduran tras el arribo a los «nuevos» territorios (dentro de las fronteras del mismo estado).

Para referirme a este proceso y sus efectos en la territorialización de los sujetos desplazados recurro al término de desterritorialización, que ha sido objeto de discusiones y análisis desde diferentes enfoques y disciplinas sociales, los cuales 
por razones de espacio y pertinencia no desarrollo, pero ejemplifico a continuación para dar cuenta de su amplitud. El término ha sido abordado desde perspectivas filosóficas, geográficas, culturales, políticas y económicas que incluyen desde debates sobre la (pos)modernidad y la globalización, en las que puede ser utilizado para referirse a la deslocalización de las empresas o a la inmaterialidad e inmediatez de los flujos financieros y comerciales — como lo que plantea Storper (2000:49) acerca de «una globalización a través de la desterritorialización» en referencia a las «cadenas de commodity globales»-, o bien, para señalar que los fenómenos de la globalización han acarreado una desespacialización de los procesos económicos, sociales y culturales, o para referirse a un debilitamiento de los Estados nación, e incluso, a El fin de los territorios — como se titula el libro de Badie (1995) —; ${ }^{3}$ hasta el concepto filosófico que desarrollan Deleuze y Guattari, para quienes la desterritorialización es un movimiento por el cual se abandona el territorio, ${ }^{4}$ es la operación de una «línea de fuga» (Deleuze y Guattari, 1980:517) y apertura a lo nuevo, siempre acompañado por un movimiento de reterritorialización, de construcción de territorio.

Retomando a estos dos autores en clave geográfica, Haesbaert (2013:13) sostiene que: «el territorio ${ }^{5}$ está vinculado siempre con el poder y con el control de procesos sociales mediante el control del espacio. La desterritorialización nunca

3 Muchos autores han cuestionado estos postulados, como sintetiza Giménez (2000:19): «economistas, sociólogos y hasta historiadores (véanse Wallerstein, 1979; Fossaert, 1994; Braudel, 1985) a los que se añaden geógrafos y analistas de la geopolítica de territorios (véanse Lacoste, 1993; Baud, 1995; Hoerner, 1996), interpretan de otro modo, sin negarlo, el fenómeno de la globalización. Según ellos, la globalización, lejos de provocar la "desterritorialización" universal, tiene por patria de origen y principal beneficiario un centro constituido por un núcleo reducido de Estadosnaciones —los más poderosos y prósperos del orbe (la tríada Estados Unidos, Europa, Japón)—, y se difunde de modo desigual por varias periferias [...] esta configuración tiene, por supuesto, un carácter territorial y es perfectamente cartografiable».

${ }^{4}$ A este concepto le otorgan una gran amplitud: «El territorio crea el agenciamiento. El territorio excede a la vez el organismo y el medio, y la relación entre ambos» (Deleuze y Guattari, 1980:513). Como explica Haesbaert (2011:105), para estos autores el concepto de territorio gana amplitud porque tiene que ver también con el pensamiento y el deseo, entendido como una fuerza «maquínica», es decir, productiva, por lo que sería posible territorializarse o construir un territorio en cualquier cosa, incluso, por ejemplo, en un libro, a partir de un conjunto integrado de agenciamientos maquínicos de cuerpos y agenciamientos colectivos de enunciación.

${ }^{5}$ El territorio implica una relación de apropiación socioespacial que «se reproduce a lo largo de un continuum que va desde la dominación política-económica más 'concreta' y 'funcional' hasta la apropiación más subjetiva o 'cultural-simbólica'» (Haesbaert, 2011:81). Aunque resulta equivocado escindir estas esferas, cada grupo social puede territorializarse, es decir, crear mediaciones espaciales que proporcionen un efectivo «poder» sobre su reproducción como grupos o individuos (Haesbaert, 2011:82-83), a través de procesos de carácter más funcional o más simbólico «dependiendo de la dinámica de poder y de las estrategias que están en juego» (Haesbaert, 2011:82). 
puede disociarse de la reterritorialización, y puede tener un sentido tanto positivo cuanto negativo».

Así es que, mientras es posible pensar la desterritorialización en un sentido positivo mediante el uso del concepto que hacen Deleuze y Guattari (1980), como salida de una antigua territorialidad y construcción de un territorio nuevo, Haesbaert hace énfasis en su sentido negativo al plantear que:

Desterritorialización, si es posible utilizar el concepto de manera coherente, nunca "total" o desvinculada de los procesos de re-territorialización, debe aplicarse a fenómenos de efectiva inestabilidad o debilidad territorial, sobre todo entre grupos socialmente más excluidos o profundamente segregados y, como tales, imposibilitados de ejercer un control efectivo sobre sus territorios (Haesbaert, 2011:258).

Este autor propone entonces trabajar la desterritorialización no solo en términos de destrucción o abandono de territorios, sino también como precarización territorial. En vinculación con las situaciones de «efectiva inestabilidad o debilidad territorial», considera que las propiedades que evidencian procesos de desterritorialización / territorialización precaria son: "la inestabilidad e inseguridad socioespacial; la fragilidad de lazos entre los grupos sociales y de estos con su espacio (tanto en términos de relaciones funcionales como simbólicas) y la movilidad sin dirección definida o la inmovilidad sin efectivo control territorial» (Haesbaert, 2011:274).

Retomo entonces los aportes de este autor para plantear que el desplazamiento forzado consiste en un proceso de desterritorialización acompañado por una reterritorialización que, a la luz de la situación particular que desarrollo, sostengo, adquiere características de una desterritorialización/territorialización precaria (Haesbaert, 2011:274).

\section{Metodología}

Con base en el método etnográfico, en este artículo abordo una modalidad concreta de movilidad forzada a partir de la situación particular de desplazamiento forzado interno por motivos de violencia política que documenté durante el trabajo de campo realizado entre 2015 y 2018 en la ciudad de San Cristóbal de Las Casas, desde un enfoque que considera «la acción violenta desde el punto de 
vista de los sujetos involucrados, a mirarla desde su perspectiva, a colocarla en el terreno mismo de la subjetividad» (Jimeno, 2007:182).

Dicho método y enfoque me han permitido recabar información acerca de los sentidos de los propios desplazados sobre los territorios y las experiencias de violencia, así como de sus identificaciones, objetivos y relaciones con organizaciones en la ciudad. Utilizo en este artículo la noción de identificación «para aludir específicamente al sentimiento de pertenencia que las personas tienen respecto de un colectivo, siempre cristalizado en una categoría disponible» (Grimson, 2010:12), la cual implica «una definición de los actores sociales y no una conclusión objetivista del investigador» (Grimson, 2010:12).

Presento entonces la situación de un grupo de $21^{6}$ personas desplazadas de Banavil, comunidad ubicada en el municipio de Tenejapa, mediante testimonios de integrantes de las familias de apellido Girón López y López Girón, con quienes he realizado entrevistas semiestructuradas y observación participante en el sitio donde residen en la actualidad y con quienes también nos hemos reunido a conversar de manera informal en diferentes espacios de la ciudad y en las oficinas del Centro de Derechos Humanos Fray Bartolomé de Las Casas (CDHFBC), cuyos miembros hicieron posible tanto el primer contacto como la construcción de vínculos de confianza con las personas desplazadas.

\section{De Banavil a San Cristóbal}

Indígenas tseltales, simpatizantes zapatistas y desplazados, así se identifican quienes fueron forzados a abandonar sus hogares en la comunidad de Banavil el 4 de diciembre del 2011. A partir de este momento, y desde hace ya más de siete años, este grupo de 21 personas reside en una colonia cerca del periférico norte en San Cristóbal de Las Casas. Aunque tuve la oportunidad de visitarlos ${ }^{7}$ en el sitio donde se encuentran desplazados, me pidieron que no especifique en mis trabajos el nombre de la colonia, ya que aún se sienten desprotegidos y amenazados.

En tanto simpatizantes del Ejército Zapatista de Liberación Nacional (EZLN), estas personas comparten ideas y discursos en torno a la resistencia, la autonomía, el acceso a la tierra, la dignidad, la defensa de derechos y sostienen que están

\footnotetext{
6 Incluyendo a niñas y niños nacidos en la situación actual de desplazamiento.

7 Pude visitarlos en la colonia donde residen en cuatro ocasiones durante 2015 y he vuelto a reunirme con ellos en distintos puntos de la ciudad en enero y febrero del 2018.
} 
«en la lucha»: este es el motivo por el cual entienden que han sido desplazadas de la comunidad de Banavil. Si bien el municipio de Tenejapa no forma parte de los Municipios Autónomos Rebeldes Zapatistas (MAREZ), la comunidad se declaró base de apoyo zapatista (BAEZLN) ${ }^{8}$ en 1996, dos años después del levantamiento armado del EZLN. Así es como Miguel López Girón resume lo que entonces ocurrió:

Porque estamos desplazados es por qué, es que en el 96, en el 1996, entramos como bases de apoyo del Ejército Zapatista de Liberación Nacional. De eso, pues ahí, en el 96 entramos los cuatro familias que conformamos, que estamos desplazados. Pues, nosotros estábamos ahí pues, bien, unidos con ellos y estábamos ahí luchando, pues, unidos. [...] Pero como algunos que nosotros conformamos dentro de la organización, que estaba dentro de la organización, pues, le gustó el apoyo que manda el gobierno y ellos salen [...] y nosotros como familia, no, como no fuimos, como nosotros no agarramos el camino del gobierno, tampoco desviar del camino, aunque nosotros ya estábamos ahí solos, pues nosotros llegamos en la organización pero sin, solos, así quedamos como simpatizantes (entrevista a Miguel López Girón, abril de 2015).

Miguel tenía en ese entonces 21 años, estaba trabajando en la Ciudad de México cuando ocurrió el desplazamiento y regresó a Chiapas para ayudar a su familia por ser quien mejor habla y comprende el español, ya que los demás se comunican casi siempre en tseltal. En el fragmento anterior explica los motivos del desplazamiento a partir de un cambio en la identificación política de la comunidad de Banavil. Sus habitantes, que fueron «bases de apoyo zapatistas» desde 1996, pasaron luego a ser «priístas» —afines al Partido Revolucionario Institucional-cuando comenzaron a recibir programas de apoyo económico del gobierno, excepto las familias hoy desplazadas que dicen haberse mantenido como «bases de apoyo zapatistas» hasta el 2000. Debido a los hostigamientos y las amenazas que denuncian haber recibido por parte de los «priístas» decidieron dejar de ser «bases» pero sin «desviar el camino» —lo que para ellos significa rechazar el consumo de bebidas alcohólicas y los programas de apoyo ofrecidos por el gobierno-, y pasaron entonces a autodenominarse «simpatizantes zapatistas»:

\footnotetext{
8 Se denomina Bases de Apoyo del Ejército Zapatista de Liberación Nacional a personas y comunidades que conforman la «base social» (no militar) del movimiento zapatista.
} 
entendemos para ser simpatizantes es seguir la idea, seguir también la idea de ellos, de pues, del Ejército Zapatista de Liberación Nacional, seguir la idea porque para nosotros también es un camino pues que abrieron también para saber defender nuestros derechos, pues, para nosotros qué es ser simpatizante es seguir luchando también, exigir pues que nos respeten nuestros derechos, pues, nuestros derechos como que nos respeten nuestros derechos de la tierra, porque el gobierno está pues metiendo su mano en nuestras tierras, por eso nosotros estamos defendiendo también la tierra, que nos respeten nuestros derechos a trabajar en la tierra (entrevista a Miguel López Girón, abril de 2015).

Aunque dejaron de ser «bases» para quedar como «simpatizantes», esto no fue suficiente para dar por finalizada la violencia política (Nagengast, 1994:114). Es que sus prácticas y discursos inspirados en ideas de autonomía y defensa de derechos del Ejército Zapatista de Liberación Nacional continuaron entrando en contradicción con las prácticas políticas partidarias de las autoridades comunales vinculadas al PRI, cuyas agresiones y amenazas persistieron con intensidad variable durante los siguientes 11 años, ${ }^{9}$ hasta devenir en un estallido de violencia extrema y desplazamiento forzado. Esta situación acompaña la observación que realiza Cruz (2007:83) con respecto a que es recurrente que entre la población desplazada en Chiapas exista una identificación sociopolítica alternativa a la hegemónica u opuesta a los partidos políticos oficiales.

La participación de autoridades de Banavil en el ejercicio de la violencia política puede ilustrarse con un fragmento del Acta de acuerdo del 23 de agosto de 2011, con firmas y sellos correspondientes a los presidentes de la Asociación de Padres de Familia, del Patronato de Obras, del Patronato de Luz y del Agua Potable, en la cual advierten: «Fijamos fecha límite el 23 de septiembre para ser desalojados [...]. Acordamos que se limpie la enfermedad de nuestro paraje porque nuestras autoridades competentes no nos han tomado en cuenta» (CDHFBC, 2011). En este fragmento, autoridades de la comunidad se refieren a los simpatizantes zapatistas de modo estigmatizante, como una «enfermedad» que acordaron «limpiar»y, aunque no especifican cuál es la acción que se proponen llevar a

9 Enmarcadas en esta situación de persecución y violencia política, las narraciones acerca de la conflictividad en la comunidad incluyen también disputas por límites entre terrenos colindantes, amenazas de muerte, cobros de multas arbitrarias, acusaciones de hechicería contra el padre de Miguel López Girón y expulsión de la escuela primaria de sus sobrinas, Lucía y Antonia López Méndez. Acerca de estas situaciones de violencia previas a la expulsión de la comunidad y sus efectos graduales en la territorialización de los simpatizantes zapatistas, véase Pecker (2018:271-277). 
cabo, el documento anticipa el desplazamiento forzado que ocurriría menos de tres meses después.

El 4 de diciembre de 2011, un grupo de 50 «priístas» se presentó en sus casas portando armas de fuego. Allí fue visto por última vez el padre de Miguel, Alonso López Luna, cuando «se lo llevaron», ${ }^{10}$ y Lorenzo López Girón, su hermano, quedó herido de bala y fue detenido. Mientras sus casas eran saqueadas e integrantes de la familia estaban siendo heridos y secuestrados, los demás escapaban sin saber hacia dónde ir:

Cuando la violencia encuentra su expresión más extrema los efectos en la territorialización son drásticos. Todos los territorios y caminos que eran transitados de manera cotidiana deben ser abruptamente abandonados y no es posible restablecer sus conexiones durante la posterior re-territorialización precaria (Pecker, 2018: 278).

Con la huida comenzó entonces el periodo de mayor desterritorialización, terror e incertidumbre, en una movilidad sin dirección definida hasta encontrar dónde asentarse en la ciudad de San Cristóbal de Las Casas.

Desde allí pusieron en marcha el proceso de denuncia que sostienen hasta la actualidad:

De acuerdo a la información documental el 4 de diciembre de 2011, en Banavil, Tenejapa, un grupo de integrantes del Partido Revolucionario Institucional (PRI) agredieron con armas de fuego a cuatro familias que son simpatizantes del Ejército Zapatista de Liberación Nacional (EZLN). Las agresiones tuvieron como resultado: la muerte de Pedro Méndez López; la desaparición de Alonso López Luna; el desplazamiento forzado de cuatro familias acusadas de ser simpatizantes zapatistas; la detención de Lorenzo López Girón quien fue herido por arma de fuego y acusado de lesiones calificadas; la detención arbitraria de Francisco Santiz López, Base de Apoyo del EZLN (BAEZLN), que se encontraba en un lugar distinto a los hechos; y lesiones a seis personas más (CDHFBC, 2013).

Este fragmento es parte de uno de los informes del Centro de Derechos Humanos Fray Bartolomé de Las Casas (también conocido como «el Frayba»), a donde recurrieron por recomendación de «otras personas que también son bases de apoyo zapatista», según comenta Miguel. Afín a este movimiento y a otros

\footnotetext{
10 Alonso López Luna fue secuestrado el 4 de diciembre de 2011 (CDHFBC, 2017) y desde entonces se halla en situación de desaparición forzada.
} 
«procesos populares y organizados en lucha», ${ }^{11}$ esta organización civil les brinda asesoramiento legal e inscribe sus denuncias de manera formal en el marco del derecho estatal y del derecho humanitario internacional:

El Frayba ha hecho diversas intervenciones públicas y privadas en diversas ocasiones para solicitarle al Gobierno de Chiapas que se atiendan las peticiones de los desplazados internos de Banavil. Sin embargo hasta la fecha no hay ninguna respuesta; con lo que el Estado no está cumpliendo con su obligación de garantizar y proteger los derechos humanos de los pueblos indígenas en Chiapas, por lo que ha violentado los convenios internacionales firmados y ratificados por el Estado mexicano, como la Convención Americana sobre los Derechos Humanos en su artículo 25; el Convenio 169 de la OIT en su artículo 14; Declaración de la Naciones Unidas sobre los Derechos de los Pueblos Indígenas en su artículo 10; la aplicación de los Principios Rectores de los Desplazamientos Internos entre otros con relación al artículo $1^{\circ}$ de la Constitución Política de los Estados Unidos Mexicanos (CDHFBC, 2013).

La vinculación con integrantes del Frayba y su asesoramiento en materia de derechos humanos les ha permitido construir su identificación como desplazados, y tener en ese centro una instalación estratégica (Grossberg, 2003:173) desde donde pueden establecer una forma particular de agencia ${ }^{12}$ orientada a un tipo de denuncia y reclamo, los «puntos de nosotros». Estos consisten en:

1. Que aparezca Alonso López Luna; 2. Retornar a Banavil; 3. Que se retiren las órdenes de aprehensión de Lorenzo López Girón y de Antonio López Girón; 4. Que no se repitan los hechos de violencia; 5 . Seguridad; 6. Reparación del daño por el saqueo de sus casas y por el robo de sus pertenencias (enumeración realizada en conjunto durante la entrevista a Pedro, Lorenzo y Miguel López Girón, abril de 2015).

11 El Centro de Derechos Humanos Fray Bartolomé de Las Casas es una organización civil sin fines de lucro fundada en 1989 por iniciativa de Samuel Ruiz García, obispo en ese entonces de la Diócesis de San Cristóbal de Las Casas. Según indica su sitio web, las actividades que realizan están focalizadas en atender, documentar y denunciar violaciones a los Derechos Humanos en el estado de Chiapas; promover el Derecho a la Libre Determinación y Autonomía de los Pueblos indígenas «Promovemos el derecho a la Libre Determinación y a la Autonomía de los Pueblos indígenas desde sus derechos a la tierra y territorio. Acompañamos procesos populares y organizativos en lucha por sus derechos, que permitan consolidar una cultura de respeto a los Derechos Humanos como condición para la paz con justicia y dignidad» (CDHFBC, s/f).

12 «La agencia constituye instalaciones estratégicas: lugares y espacios específicos que definen formas particulares de agencia $v$ dan poder a poblaciones particulares. [...] La agencia es el producto de diagramas de movilidad y emplazamiento que definen o cartografían los posibles lugares y modos en que pueden detenerse y colocarse vectores específicos de influencia» (Grossberg, 2003:173). 
Estos puntos son retomados por el equipo de comunicación social del Frayba en la redacción de boletines informativos y comunicados, los cuales hacen parte de las estrategias que llevan adelante en concordancia con su objetivo de proporcionar «información a la sociedad a través de los medios de comunicación sobre violaciones a derechos, para transformarla en acciones que obliguen al Estado a proteger y garantizar el ejercicio de los Derechos Humanos» (CDHFBC, 2019).

Otro de los vínculos que los desplazados destacan haber construido luego de su desplazamiento es con el movimiento católico el Pueblo Creyente, en la parroquia San Antonio de Padua, ${ }^{13}$ municipio de Simojovel. Encabezado por el padre tsotsil Marcelo Pérez Pérez, este movimiento organiza convocantes peregrinaciones para protestar contra la pobreza, la corrupción y la violencia en Chiapas.

Así, por ejemplo, del 23 al 26 de marzo de 2015, los desplazados de Banavil peregrinaron 240 kilómetros junto con otras 15000 personas, desde Simojovel hasta Tuxtla Gutiérrez, capital del estado. Al finalizar el recorrido, leyeron un pronunciamiento:

Como pueblo creyente de Simojovel nuestra lucha es pacífico y no a la violencia armada, pensamos que en esta ocasión es necesario sumar los sufrimientos y peticiones de los distintos participantes que acudieron al llamado de esta peregrinación y podamos incluir la palabra colectiva de quienes con su andar denunciamos las distintas injusticias que viven cotidianamente. En este pronunciamiento final, los distintos reclamos de justicia han sido divididos en diferentes puntos que evidencian de forma clara la situación que como estado y país estamos padeciendo (Consejo Parroquial de Simojovel, 2015).

Como puede leerse en el fragmento anterior, al intercalar primera y tercera persona del plural, aquellas peticiones y sufrimientos que «viven cotidianamente» las personas que acudieron a la peregrinación son incluidos en el pronunciamiento del Pueblo Creyente como parte de una situación general y de una denuncia más amplia "que como estado y país estamos padeciendo». En este comunicado indican cuáles son los reclamos de justicia y, punto por punto, detallan sus ejes: «Primer punto: alto a la impunidad y corrupción» (donde incluyen, por ejemplo, pedidos de auditorías por desvíos de recursos y enriquecimiento ilícito en varios municipios, justicia y aparición con vida de los 43 estudiantes de Ayotzinapa, libertad a presos políticos, desmantelamiento de grupos paramilitares, alto al

\footnotetext{
13 Perteneciente a la Diócesis de San Cristóbal de Las Casas.
} 
tráfico de armas y respeto a la autonomía y libre determinación de los pueblos); «Segundo punto: no a los megaproyectos» (donde dicen «no»a, por ejemplo, presas hidroeléctricas, «supercarreteras» y proyectos mineros de la zona Norte y Altos de Chiapas); «Tercer punto: no a las reformas estructurales» (expresan su rechazo a las «reformas estructurales del capitalismo neoliberal que permiten la exploración y explotación acarreando despojo de tierras y territorios empobreciendo a nuestros pueblos», como el aumento de las tarifas de la energía eléctrica y la privatización del agua y los recursos naturales); «Cuarto punto: demandas de infraestructura» (exigen pavimentación de calles, construcción de caminos, puentes y mejoras de servicios públicos); «Quinto punto: desplazamiento» (agregan «No al desplazamiento forzado en Chiapas y en México» y «Justicia, verdad y retorno para los desplazados de Banavil, Tenejapa y Primero de Agosto de Las Margaritas»), y, por último, "Sexto punto: denuncia y solidaridad» (mencionan 21 peticiones de diferentes procedencias y de diversa índole, entre las cuales incluyen la «búsqueda y aparición con vida de Alonso López Luna. Cancelación de órdenes de aprehensión de Antonio y Pedro López Girón desplazados de Banavil, Tenejapa»). Así, los reclamos de los desplazados de Banavil (justicia, verdad, retorno, aparición con vida de Alonso y cancelación de las órdenes de aprehensión de sus hijos Antonio y Pedro) fueron incluidos en los puntos quinto y sexto del pronunciamiento del Pueblo Creyente, leído al finalizar la peregrinación del 26 de marzo de 2015. Un mes más tarde, Miguel me comentó al respecto:

Pues, este que pasó, estuvo, estuvimos en la peregrinación, el 23 y 26. [...] Pues también estuvimos a exigir sus demandas también, pues a solidarizarse con ellos, porque el sufrimiento también del Pueblo Creyente del Simojovel, pues ese es el mismo dolor que tenemos, pues no hay, no hay diferente el dolor, sino que es el mismo, es el mismo dolor, el dolor de ellos también sentimos el mismo dolor, el dolor que nosotros tenemos, sentimos el dolor que tenemos, por eso pues nos organizamos juntos con ellos (entrevista a Miguel López Girón, abril de 2015).

En este fragmento de entrevista, Miguel expresa empatía y solidaridad recíproca entre los desplazados de Banavil y el Pueblo Creyente de Simojovel. Esta identificación afectiva, según sostienen Jimeno, Castillo y Varela (2015:252): «posibilita la conformación de comunidades emocionales que se configuran alrededor de una versión compartida de los sucesos de violencia y también en torno al sentimiento común de repudio moral para con los responsables de esos hechos». 
De esta manera, los desplazados de Banavil se identifican con un grupo más amplio, con una comunidad emocional que les permite «salir de ese dolor al compartirlo con otros en forma de acción organizada» (Jimeno, 2011:45), restableciendo lazos para la acción ciudadana (Jimeno, 2007:169-170). En esta comunidad emocional comparten tanto dolores como perspectivas políticas y religiosas (afines a la teología de la liberación y al movimiento zapatista), dirigiendo sus reclamos y repudios morales hacia el Estado mexicano en sus diferentes poderes y niveles de gobierno.

En vinculación con los sufrimientos que expresan los desplazados de Banavil, un aspecto recurrente en sus denuncias públicas y en las conversaciones que han mantenido conmigo entre los años 2015 y 2018, es el contraste entre la tristeza «aquí» en San Cristóbal de Las Casas y la vida «allá» en Banavil:

Miguel: [traduce al español las palabras de Petrona, que se comunica en tseltal] —Pues... ella dice que aquí, también aquí pues sufre mucho, sí, sufre mucho como ella no están acostumbrado salir a trabajar, pues... es diferente vivir aquí, sí, es lo que dice. Carolina: — ¿Y cómo era vivir allá?

Miguel traduce ahora a tseltal y luego lo explica en español:

Miguel: —Pues... allá en Banavil, pues dice que vivía feliz allá, como es nuestros terrenos, pues ahí vive feliz. Se puede salir a hacer sus cosas... a pasear un rato, trabajar un rato y pues ya regresar en la casa. Pues aquí no es lo mismo, no es lo mismo, ya como ella dijo, pues aquí no es nuestra el tierra donde estamos, pues está muy difícil para ella vivir aquí en la ciudad (entrevista a Miguel y Petrona López Girón, abril de 2015).

Al preguntarle cómo es Banavil, Miguel traduce a su hermana mayor Petrona López Girón, de 31 años, que contrasta su respuesta con la situación «aquí» en San Cristóbal de Las Casas. Cuando tenían sus terrenos, dice, vivía feliz. Es que los discursos acerca de cómo era la vida en Banavil y sus comunidades aledañas, ${ }^{14}$ oscilan entre recuerdos violentos — de hostigamientos y persecución política- y otros recuerdos felices y apacibles, como mencionan en el fragmento anterior, relacionados con el trabajo en sus terrenos, la siembra de sus milpas y la preparación de comidas con sus cosechas. «Pues aquí no es lo mismo», traduce Miguel. Este es un aspecto clave en su identificación como desplazados, que tanto denuncian las violencias sufridas «allá», como su deseo de retorno, a la vez

\footnotetext{
14 Me refiero a las comunidades de Cruz Tzibaltik y Santa Rosa, entre las cuales se movían para trabajar en sus cultivos, con su ganado, para buscar leña, para comer juntos o dormir. La movilidad «bajo control» entre estas comunidades era un aspecto fundamental de su territorialización (Pecker, 2018:267-269).
} 
que expresan la fragilidad de lazos en sus relaciones funcionales y afectivas, en el espacio donde hoy «aquí» residen, en una situación de desterritorialización / territorialización precaria (Haesbaert, 2011:274), dada la inestabilidad e inseguridad socioespacial que experimentan.

Construidas con paredes de madera, techos de chapa y telas cubriendo los ingresos a cada subdivisión, son dos las casas «provisorias» —una «prestada» que se ubica casi en la base del cerro y otra «rentada» unos 300 metros más arriba- entre las cuales se distribuyen para vivir. En ambas viviendas cuentan con luz eléctrica y agua; sin embargo, esta última no es potable y su suministro es discontinuo e irregular. No tienen gas, aunque tampoco en Banavil utilizaban este servicio. Sin embargo, antes del desplazamiento podían recoger leña en terrenos que consideraban propios, mientras que ahora, excluidos de dichos lugares, se ven obligados a comprar descartes de aserrín en una empresa maderera.

Al traducir a su madre, Antonia Girón López, de 62 años, Miguel enfatiza que lo que marca la diferencia en su forma de vida actual es la falta de acceso a sus tierras:

siempre está feliz con el frijol... el maíz que tenían allá en Banavil. Pero aquí no, pues aquí se compra todo, también aquí maíz, pues el frijol también se compra, por eso a veces se pone triste cuando ve que ya no, ya no hay frijol o maíz para comer, por eso quiere regresar allá, para sigue trabajar en la tierra [...] pues aquí el día pues... siempre sale a lavar... los días la pasa triste, porque es muy difícil para ella, es lo que dice. Le pasa todos los días, siempre sale a trabajar, viene la tristeza en el camino, así pasa los días (entrevista a Antonia Girón López y Miguel López Girón, abril de 2015).

Desde su dimensión afectiva, esto implica la añoranza del lugar considerado propio, de sus quehaceres y rutinas de la vida cotidiana, donde «siempre está feliz», a la vez que en su aspecto material-funcional se ven afectados por verse obligados a comprar lo que antes podían ellos mismos producir («ya no hay frijol o maíz para comer, por eso quiere regresar allá»).

Así es que en esta desterritorialización / territorialización precaria (Haesbaert, 2011:274) la dificultad para acceder a recursos necesarios para su reproducción y las dificultades económicas perjudicaron su alimentación y sus condiciones de vida de tal manera que incluso provocaron la muerte de una de las niñas desplazadas, Antonia López Méndez, sobrina de Miguel, quien sufrió un edema cerebral a los 11 años de edad y que, según su familia, «murió de tristeza». Por eso, pese a la violencia extrema que han vivido en Banavil, el deseo del retorno se 
sostiene porque «aquí», insisten, todo es muy diferente y sufren. «Pues aquí el día pues... siempre sale a lavar... los días la pasa triste», dice Miguel traduciendo a su madre.

Como sostiene Mercado (2013:116), «los hombres y las mujeres viven el desplazamiento de una manera diferenciada». Es que ofrecerse a lavar o limpiar para otras personas no era una tarea habitual para las mujeres de su familia, cuyas actividades eran dentro del hogar, en sus milpas y terrenos ubicados en Banavil y comunidades aledañas. Por lo tanto, no solían ir más allá del municipio de Tenejapa ni realizar trabajos remunerados. Sin embargo, ahora en la ciudad se ven obligadas a hacerlo para intentar conseguir algo de dinero adicional. Tal es el caso de su hermana mayor, Petrona, y también de Ana López Girón (16 años), su hermana menor, quien está trabajando como empleada doméstica:

Carolina: -Entonces... te quería preguntar, ¿Cómo es vivir ahora en San Cristóbal para ti?

Ana: [habla en tseltal y Miguel traduce] —Pues, aquí... un poco bien... un poco triste. Carolina: - ¿Y qué te pone triste?

Ana (responde en español): Ahorita... viene mi tristeza...es que aquí no está mi papá, no está mi papá y cuando está mi papá nunca me puede, no, no va a dejar a salirse a trabajar, eso estoy pensando, ahorita aquí no está mi papá (entrevista a Ana López Girón, febrero de 2018).

Con los ojos llenos de lágrimas, Ana dice que su padre no hubiese permitido que saliera a trabajar $y$, de esta manera, con esa frase, enlaza dos situaciones que son causa de suma tristeza para ella: la desaparición forzada de Alonso, su padre, y las condiciones actuales de vida y trabajo en la ciudad. Lo único que dice apreciar de su trabajo en San Cristóbal es estar aprendiendo español. Como puede observarse en el fragmento anterior, si bien Miguel traduce al tseltal la primera pregunta, luego Ana comprende la siguiente y responde en español. Así nos desenvolvimos en el transcurso de las conversaciones, Miguel fue traduciendo al tseltal las partes que sus familiares no comprendían o no querían decir en este idioma. Esta diferencia en el manejo del español, así como el acceso a trabajos remunerados, se encuentra vinculada con la condición de género. Además de trabajar en sus milpas cuando aún vivían en Banavil, Miguel y sus hermanos mayores (Antonio, Lorenzo y Pedro, de entre 30 y 40 años de edad) solían emplearse en oficios temporales remunerados, como peones, albañiles o en tiendas comerciales, en otros municipios e incluso fuera del estado de Chiapas, por ejemplo, 
en la Ciudad de México (Pecker, 2018:266), lo cual continúan realizando hasta la actualidad. A diferencia de las mujeres, ellos ya manejaban el idioma español cuando sucedió el desplazamiento forzado. Aún así, también entre los hombres existe una variación en el grado de manejo y/o de predisposición para utilizarlo. En este sentido, en febrero de 2018, durante mi última estadía en la ciudad, Miguel estaba realizando trabajos en los cuales su desempeño en el idioma resulta central. Entre el tseltal, el tsotsil y el español, Miguel ha estado haciendo traducciones para una radio que pertenece a la Red de Medios Libres, ${ }^{15}$ afín al movimiento zapatista, y para la organización de Médicos Sin Fronteras. ${ }^{16}$

\section{Reflexiones finales}

El abordaje etnográfico de una modalidad concreta de movilidad forzada, como lo es el fenómeno del desplazamiento forzado interno, me ha permitido analizarlo como un proceso de desterritorialización / territorialización precaria, caracterizando sus particularidades (movilidad sin dirección definida; inestabilidad e inseguridad socioespacial; fragilidad de lazos con el espacio) en relación con las identificaciones, las experiencias y los sentidos de los propios desplazados.

Quienes se identifican como simpatizantes zapatistas de la comunidad de Banavil abandonaron sus hogares el 4 de diciembre de 2011 por motivos de violencia política; en concreto, por un ataque armado que los llevó a huir sin dirección para salvaguardar sus vidas. Las hostilidades se atribuyen a personas afines al PRI, según las narraciones de los propios desplazados y los informes elaborados por el Centro de Derechos Humanos Fray Bartolomé de Las Casas. Los hechos involucraron a autoridades de la comunidad de Banavil, quienes han dejado registros escritos de la estigmatización construida contra los simpatizan-

15 La Red de Medios Libres de Chiapas consiste en «un grupo de colectivos y organizaciones civiles que hacemos medios alternativos, libres, independientes en Chiapas, principalmente para difundir la información del movimiento social [...] del que somos parte. Nuestros colectivos y organizaciones civiles son diversos y caminan de manera autónoma, pero en esta red donde nos articulamos nos une el ejemplo zapatista y la sexta declaración de la selva lacandona como marcos de referencia en la lucha que hacemos desde nuestra trinchera, que son los medios de comunicación» (Red de Medios Libres, s./f).

16 Entre los meses de diciembre y febrero de 2018 la organización de acción médica humanitaria Médicos Sin Fronteras (MSF) realizó una serie de visitas a comunidades del municipio de Chalchihuitán, en la región de los Altos de Chiapas, para brindar atención médica y psicológica a personas desplazadas «que salieron huyendo de sus casas después de los últimos incidentes de seguridad del final de octubre del 2017 donde fue asesinado un residente de Canalumtic» (Médicos Sin fronteras, 2018). 
tes zapatistas, marcados como peligro o amenaza (como una «enfermedad» que debe ser «limpiada»).

El desplazamiento forzado resultante de dicha violencia les ha significado la pérdida de su control territorial y los ha dejado inmersos en una situación de inestabilidad e inseguridad socioespacial, de fragilidad de lazos con el espacio tanto en términos de sus relaciones funcionales y materiales como afectivas. Mientras que el retorno se encuentra aún vedado por el miedo a recibir nuevas agresiones, solicitan que no sea siquiera mencionado el nombre de la colonia donde hoy residen, pues consideran que se trata de un territorio ajeno, provisorio, donde temen por su integridad física y donde las condiciones materiales de vida, precarias e insalubres, han llevado al fallecimiento de Antonia López Girón, quien, según sus familiares, «murió de tristeza».

La fragilidad de los lazos con este territorio («aquí») y su deseo / imposibilidad de retorno a aquellos considerados propios («allá») son expresados mediante la reiteración de referencias dicotómicas. Estas referencias («aquí»/ «allá») y los sentimientos (tristeza / felicidad) que los sujetos asocian con los territorios de partida y de llegada buscan establecer diferencias contrastantes, irreconciliables, entre los territorios que son considerados propios y ajenos, como modos de expresar su deseo de retorno y en correspondencia con su identificación como desplazados.

En este sentido, la principal diferencia que marcan entre ambos es la falta de acceso a la tierra, tanto desde un plano material como afectivo. Las narraciones acerca de la vida en la comunidad de Banavil como lugar anhelado para el retorno son intercaladas por otras que hacen referencia a las amenazas y a la violencia, y su identificación política como simpatizantes zapatistas "en la lucha» adquiere relevancia para explicar el conflicto con miembros del PRI y los motivos que originaron su desplazamiento forzado.

Es decir que en su actual situación de desterritorialización / territorialización precaria, los sujetos ponen en juego sus identificaciones en la construcción de relaciones con organizaciones que los acompañan en sus objetivos y proyectos de justicia y retorno, y en la elaboración y puesta en práctica de un tipo particular de denuncia y reclamo (a lo cual se refieren como «los puntos de nosotros»).

Mediante una identificación afectiva y política, los desplazados de Banavil participan de la organización cristiana del Pueblo Creyente de Simojovel (afín a la teología de la liberación y al movimiento zapatista), comunidad emocional en la cual «comparten dolores» y peregrinan difundiendo sus reclamos y repudios 
junto a otros campesinos e indígenas de los Altos de Chiapas, mientras trabajan junto con el Centro de Derechos Humanos Fray Bartolomé de Las Casas -también afín al movimiento zapatista y a los «procesos populares y organizados en lucha»- para exigir el cumplimiento de sus derechos e inscribir sus denuncias de manera formal en el marco del derecho estatal y el derecho humanitario internacional. En este sentido, su identificación como desplazados se plantea como una instalación estratégica, que se habilita a partir de sus relaciones previas con bases de apoyo zapatistas y, mediante ellas, por su vinculación y trabajo posterior con el Frayba.

Como muchos otros indígenas provenientes de los Altos de Chiapas, las personas con quienes trabajé comparten su lugar actual de residencia en San Cristóbal de Las Casas: colonias ubicadas en los bordes de la ciudad, cercanas al periférico norte.

La necesidad de recurrir a trabajos remunerados en la ciudad para complementar la falta de acceso a la tierra afecta de manera diferencial a las mujeres, quienes no solían hacerlo cuando vivían en su comunidad.

Las opciones de trabajo están condicionadas por el género y el manejo del idioma español. Los empleos a los que pueden acceder en San Cristóbal de Las Casas son, por ejemplo, en el caso de las mujeres, de lavar ropa (Antonia Girón López y Petrona López Girón) o como empleadas domésticas (Ana López Girón); y los hombres, que generalmente poseen mayores conocimientos del idioma español, suelen ser contratados para trabajar como albañiles, peones o empleados en comercios tanto dentro como fuera de la ciudad, prácticas que sostenían desde antes de haber sido forzados a abandonar su comunidad.

En el caso de Miguel López Girón, su manejo del español, el tsotsil y el tseltal le ha abierto también acceso a una ocupación remunerada de traducción para medios de comunicación locales, afines a su identificación política, y para la organización internacional de Médicos Sin Fronteras. Aunque estas no sean opciones de trabajo que puedan considerarse habituales para las personas indígenas en la ciudad, dan razón de algunas de las particularidades de San Cristóbal de Las Casas, que opera como uno de los centros más importantes de la región de los Altos de Chiapas en el que confluyen experiencias de conflictos y trayectorias de gran diversidad política y cultural. 


\section{Fuentes de consulta}

Angulo Barredo, Jorge Ignacio, 2003, «Migraciones y asentamientos de población indígena en San Cristóbal de Las Casas. Un recuento y caracterización», Anuario de Estudios Indígenas, IX, San Cristóbal de Las Casas, Instituto de Estudios Indígenas/ Universidad Autónoma de Chiapas, pp. 63-82.

Arana Cedeño, Marcos y María Teresa del Riego, 2012, Estudio sobre los desplazados por el conflicto armado en Chiapas, México, Fondo para el logro de los ODM/ Programa Conjunto por una Cultura de Paz.

Badie, Bertrand, 1995, La fin des territoires, París, Fayard.

Cañas Cuevas, Sandra, 2011, «Los indígenas en San Cristóbal de Las Casas: El derecho a la ciudad», en Adriana Terven Salinas, Alejandro Vázquez Estrada y Bernardo Romero Vázquez (coords.), Miradas diversas. Desbordando el indigenismo. Pueblos indios, sociedad y Estado en el México del tercer milenio, volumen I, México, Universidad Autónoma de Querétaro, pp. 165-192.

Centro de Derechos Humanos Fray Bartolomé de Las Casas (CDHFBC), 2011, "Acta de Acuerdo», Expediente Caso Banavil, tomo I, agosto 23, San Cristóbal de Las Casas, Chiapas, Centro de Derechos Humanos Fray Bartolomé de Las Casas.

CDHFBC, 2013, Siguen en situación precaria e inhumana las 13 personas desplazadas de la comunidad de Banavil simpatizantes del EZLN, Boletín 9, San Cristóbal de Las Casas, Chiapas, Centro de Derechos Humanos Fray Bartolomé de Las Casas.

CDHFBC, 2017, Omisión del Estado mexicano por desaparición de Alonso López Luna. A seis años de impunidad, su familia en desplazamiento forzado continúa la exigencia de justicia hasta encontrarlo, Boletín 19, San Cristóbal de Las Casas, Chiapas, Centro de Derechos Humanos Fray Bartolomé de Las Casas.

CDHFBC, 2019, «Equipos de trabajo», en <https://frayba.org.mx/equipos-de-trabajo/> (consulta: 02/06/19).

CDHFBC, s./f, «Sobre nosotros», en <https://frayba.org.mx/sobre-nosotros/> [consulta 01/06/2019].

Chamberlin, Michael, 2013, «El desplazamiento forzado como estrategia de guerra en Chiapas», en Oscar Torrens (coord.), El desplazamiento interno forzado en México. Un acercamiento para su reflexión y análisis, México, Centro de Investigaciones y Estudios Superiores en Antropología Social/El Colegio de Sonora/Senado de la República, LXII Legislatura, Comisión de Biblioteca y Asuntos Editoriales, pp. 33-52.

Comisión Mexicana de Defensa y Promoción de los Derechos Humanos (CMDPDH), 2019, Episodios de desplazamiento interno forzado masivo en México. Informe 2018, México, Comisión Mexicana de Defensa y Promoción de los Derechos Humanos.

Comisión Nacional de los Derechos Humanos (CNDH), 2016, «Informe especial sobre desplazamiento forzado interno (DFI) en México», México, Comisión Nacional de los Derechos Humanos, en <http://informe.cndh.org.mx/uploads/menu/15008/2016_ IE_DesplazadosD.pdf> [consulta: 01/06/2019].

Consejo Parroquial de Simojovel, 2015, «Comunicado final de la magna peregrinación desde Simojovel hasta Tuxtla», en <https://espoirchiapas.blogspot.com/2015/03/ comunicado-final-de-la-magna.html> [consulta: 03/06/2019]. 
Coraza de los Santos, Enrique, 2018, «Movilidades forzadas. Cuando moverse es una estrategia de vida», Ecofronteras, 22(62), pp. 18-20.

Cruz Burguete, José Luis, 2007, «Las condiciones del desplazamiento interno en Chiapas», en José Emilio Rolando Ordóñez Cifuentes (coord.), Migración: pueblos indígenas y afroamericanos: XV Jornadas Lascasianas Internacionales, México, Instituto de Investigaciones Jurídicas-Universidad Nacional Autónoma de México, pp. 67-90.

Deleuze, Gilles y Félix Guattari, 1980, Mil mesetas. Capitalismo y esquizofrenia, Valencia, Pre-textos.

Giménez, Gilberto, 2000, «Territorio, cultura e identidades. La región socio-cultural», en Rocío Rosales Ortega (coord.), Globalización y regiones en México, México, Facultad de Ciencias Políticas y Sociales-UNAM /Miguel Ángel Porrúa.

Grimson, Alejandro, 2010, "Cultura, identidad: dos nociones distintas», Social Identities, 16(1), pp. 63-79.

Grossberg, Lawrence, 2003, «ldentidad y estudios culturales: ¿no hay nada más que eso?», en Stuart Hall y Paul du Gay (comps.), Cuestiones de identidad cultural, Buenos Aires, Amorrortu, pp.148-180.

Haesbaert, Rogerio, 2011, El mito de la desterritorialización. Del fin de los territorios a la multiterritorialidad, México, Siglo XXI Editores.

Haesbaert, Rogerio, 2013, «Del mito de la desterritorialización a la multiterritorialidad», Cultura y representaciones sociales, 8(15), septiembre, pp. 9-42.

Jimeno, Myriam, 2007, «Lenguaje, subjetividad y experiencias de violencia», Antípoda, 5, julio-diciembre, pp. 169-190.

Jimeno, Myriam, 2011, «Después de la masacre: la memoria como conocimiento histórico», Cuadernos de Antropología Social, 33, enero-julio, pp. 39-52.

Jimeno, Myriam, Daniel Varela y Ángela Castillo, 2015, Después de la masacre: emociones y política en el Cauca indio, Bogotá, Universidad Nacional de ColombiaFacultad de Ciencias Humanas-Centro de Estudios Sociales/Instituto Colombiano de Antropología e Historia.

Martínez Velasco, Germán, 2005, «Conflicto étnico y migraciones forzadas en Chiapas», Política y Cultura, 23, pp. 199-201.

Médicos Sin Fronteras, 2018, «México: atención médica a los desplazados en Chiapas», en <https://www.msf.org.ar/actualidad/mexico-atencion-medica-desplazados-chiapas $>$ (consulta 03/06/19).

Mercado Mondragón, Jorge, 2013, «La perspectiva de género en el estudio de las mujeres en condición de desplazamiento», en Oscar Torrens (coord.), El desplazamiento interno forzado en México. Un acercamiento para su reflexión y análisis, México, CIESAS/EI Colegio de Sonora/Senado de la República, LXII Legislatura, Comisión de Biblioteca y Asuntos Editoriales, pp. 113-154.

Nagengast, Carole, 1994, «Violence, Terror, and the Crisis of the State», Annual Review of Anthropology, 23, pp.109-136.

Organización de las Naciones Unidas (ONU), 1998, «Principios Rectores de los desplazamientos internos», en Francis M. Deng, Intensificación de la promoción y el fomento de los derechos humanos y las libertades fundamentales, en particular la cuestión del programa y los métodos de trabajo de la comisión derechos humanos, éxodos en masa y personas desplazadas, Informe, $54^{\circ}$ periodo de sesiones, en <https:// www.acnur.org/fileadmin/Documentos/BDL/2001/0022.pdf> (consulta 03/06/19). 
Pecker Madeo, Carolina, 2018, «Dibujos y caminos. Los desplazados de Banavil en Chiapas», Antropología Experimental,18, pp. 263-278.

Periódico Oficial del Estado de Chiapas, 2012, "Ley para la prevención y atención del desplazamiento interno en el Estado de Chiapas», Decreto 158, 355, 22 de febrero, México, en <http://forodfi.cndh.org.mx/Content/doc/Normativo/Ley-DPI-Chiapas. pdf $>$

Red de Medios Libres, s./f, «Medios libres Chiapas», en <http://komanilel.org/red-demedios-libres-chiapas/> (consulta 03/06/19).

Rivera Farfán, Carolina, 2013, «Creencias y prácticas religiosas censuradas. Expulsión de evangélicos indígenas por cambio de adscripción religiosa», en Oscar Torrens (coord.), El desplazamiento interno forzado en México. Un acercamiento para su reflexión y análisis, México, CIESAS/El Colegio de Sonora/Senado de la República, LXII Legislatura, Comisión de Biblioteca y Asuntos Editoriales.

Robledo Hernández, Gabriela, 2012, «Cruzando fronteras. De las comunidades corporadas cerradas a las comunidades transfronterizas de los indígenas chiapanecos», LiminaR, Estudios sociales y humanísticos, 10(1), junio, pp. 104-121.

Rus, Jan, 2009, «La nueva ciudad maya en el valle de Jovel: urbanización acelerada, juventud indígena y comunidad en San Cristóbal de Las Casas», en Marco Estrada Saavedra (ed.), Chiapas después de la tormenta, México, El Colegio de México / Gobierno del Estado de Chiapas-Cámara de Diputados, LX Legislatura, pp. 169-219.

Storper, Michael, 2000, «Globalization and Knowledge Flows: An Industrial Geographer's Perspective», en John H. Dunning (ed.), Regions, Globalization and the Knowledge based Economy, Oxford, Oxford University Press.

Velázquez Moreno, Ana Laura, 2017, Desplazamiento interno por violencia en México. Causas, consecuencias y responsabilidades del Estado, México, Comisión Nacional de los Derechos Humanos.

\section{Cómo citar este artículo:}

Pecker Madeo, Carolina, 2019, «En desplazamiento forzado: desde Banavil, Tenejapa, hacia San Cristóbal de Las Casas», Revista Pueblos y fronteras digital, volumen 14, e-425. https://doi.org/10.22201/cimsur.18704115e.2019.v14.425 